\title{
Relações semânticas: predicação e papéis temáticos
}

\author{
Carlos Franchi \\ Unicamp/Usp \\ Márcia Cançado \\ Universidade Federal de Minas Gerais
}

\section{OBSERVAÇÃO PRELIMINAR}

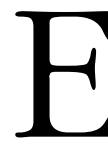

stes textos, de caráter descritivo, se destinam exclusivamente a oferecer um suporte ao curso dirigido pelo primeiro autor sobre alguns temas de semântica orientados para uma teoria gramatical. Fazem parte de uma pesquisa que vem sendo desenvolvida e cujos resultados deverão ser publicados em dois livros um, em co-autoria (sobre a teoria das relações semânticas, mais conhecidas hoje como "relações temáticas"), o outro, de responsabilidade do primeiro autor (sobre teoria gramatical), voltado para os aspectos teóricos de um modelo de gramática. Trata-se, pois, de uma reflexão que, embora bastante consolidada, se apresenta em uma 
primeira versão resumida, densa e recortada. Deixamo-la, pois, inteiramente aberta em dois sentidos: por um lado, temos consciência de que não podemos discutir neles várias questões a que se dedicam outros textos mais específicos e detalhados; por outro, como material de trabalho ("working papers") os textos se colocam para discussão, sugestões e críticas que os emende e enriqueça.

Por isso mesmo, solicitamos aos colegas participantes do curso e leitores que evitem fazer deles referências e citações, aguardando uma versão redigida como "definitiva" - menos provisória. Em um primeiro texto, discutimos uma noção central da teoria que desenvolvemos, a Predicação, como correlato semântico das operações sintáticas no componente de base da gramática. Entendemos que a teoria das relações temáticas diz respeito ao conteúdo semântico diferenciado das predicações: assim, os dois textos seguintes, diretamente resumidos da tese de doutorado da segunda autora, buscam definir com maior precisão essas relações e o alcance de um princípio projetivo e interpretativo de hierarquia temática. O último texto exemplifica o alcance da teoria em um domínio descritivo particular, a teoria da adjunção. Devemos, no entanto, desde logo, apontar muito resumidamente alguns pressupostos que deteminam a orientação teórica e as análises descritivas.

\section{INTRODUÇÃO}

Interessamo-nos por essas noções - predicação, relações temáticas, ${ }^{1}$ estruturas de adjunção - sempre do ponto de vista de uma teoria lingüística e, pois, em um plano simbólico, ou seja como conceitos de uma teoria gramatical. Esta, pressupomos compor-se de uma sintaxe e semântica representacional (uma semântica do sentido) relativamente autônomas, igualmente estruturadas, associadas não somente por regras de correspondência (interpretativas), mas ainda por uma interação persistente em todo o processo construtivo das expressões das línguas naturais. ${ }^{2}$

Assumimos, pois, um princípio metodológico de "transparência" desses dois componentes, ${ }^{3}$ ou seja, a forma sintática e a forma lógico- 
semântica, embora autônomas, são estreitamente correlacionadas: objetos abstratos, operações construtivas e esquemas resultantes, no sistema sintático, possuem um correlato no sistema semântico, a que se associa por direta de interpretação. No que é relevante a nosso tema, viso a tornar precisa uma relação lingüística de Predicação como correlato abstrato das operações construtivas dos objetos sintáticos complexos. Embora prefiramos operar com um sistema aplicacional combinatório (CURRY e FEYZ, 1958; FRANCHI, 1976) sobre constantes lexicais, não excluímos pensar a relação de predicação, tal como se define aqui, como correlato semântico de operações como "merge" (CHOMSKY, 1995-b) ou concatenação (EPSTEIN, 1995). Restrinjo, porém, a aplicação das regras combinatórias a constantes lexicais, objetos fonologicamente realizados e adjacentes na seqüência dos constituintes das expressões lingüísticas.

Restringimo-nos, ainda, nestes textos, à análise das operações envolvendo as categorias substantivas (ou descritivas) no sentido de CHOMSKY (1995-b) que, elas só, se relacionam predicativamente. ${ }^{4}$ Esta restrição se justifica em uma concepção da semântica que contém pelo menos três planos de interpretação. No primeiro se constroem representações da "realidade" - um sistema de referência envolvendo categorias (como evento, ação, estado, processo; coisas, pessoas, propriedades, etc.), relações (particularmente a predicação expressa pelo conteúdo semântico das relações temáticas), funções (como predicado e argumentos associados aos papéis temáticos). ${ }^{5}$ O segundo corresponde a processos dêiticos e quantificacionais, uma classe fechada de categorias funcionais (no sentido da gramática gerativa) - elementos lexicais e flexionais que associam essas representações a determinados estados de fato. Contrapõem-se, assim, as relações predicativas às relações delimitativas (para usar uma distinção de BIERWISH (1970)), estas como coordenadas que orientam a interpretação do sentido das expressões à sua referência. ${ }^{6}$ Enfim, no terceiro plano, interpretam-se os recursos expressivos que remetem aos modos de organização da informação e do discurso, a relações como as de tópico/comentário, foco/pressuposição, tema/ 
rema, expressas geralmente, nas línguas naturais, pelos diferentes modos de construção de orações com o mesmo conteúdo descritivo. ${ }^{7}$ Não cuidaremos aqui do segundo plano e nos referiremos somente em termos muito gerais ao terceiro.

Essa perspectiva já nos municia com alguns (meta)critérios intuitivos de necessidade conceitual, relevância e adequação. Entretanto, trata-se, em alguns aspectos, de um processo estipulativo com que estabeleço as restrições que delimitam o estatuto dessas noções na teoria e cujas conseqüências somente se poderão avaliar pela adequação descritiva e explicativa da gramática das línguas naturais que com elas se alcancem. ${ }^{8}$ Sempre são estipulações necessárias para que nos comprometamos, autores e leitores, com o quadro de referência em que os textos devem ser compreendidos.

O que se nos impõe, inicialmente, é oferecer um razoável suporte intuitivo e empírico às decisões, ou seja, às noções e relações que, postas aqui em caráter informal e descritivo, devem representar-se estruturalmente em qualquer teoria gramatical explícita e explicativa.

\section{NOTAS}

${ }^{1}$ Os termos relação temática (theta-relation), papel temático (theta-roles), rede temática (theta-grid) e similares vêm sendo habitualmente utilizados desde GRUBER (1965) e JACKENDOFF (1972). Utilizo-os para facilitar a referência entrecruzada à bibliografia gerativista, embora reconheça a impropriedade do termo. De fato, seu uso deriva de admitir-se um papel considerado como a função fundamental e, ao mesmo tempo, a mais neutra e a menos marcada, a que Gruber chamou tema para aproximar o termo da noção de tema, tal como a utiliza, por exemplo, o Círculo Lingüístico de Praga. Para Gruber, toda oração comporta um tema (e um Tema), que coincide com o sujeito gramatical de verbos intransitivos (ergativos), dos verbos estativos, e com o objeto de verbos transitivo-ativos ou transitivo-causativos. Ver a crítica ao uso desse termo em CANÇADO (1995, p. 76-77, 113).

2 "Autonomia" deve-se, pois, compreender não como a inexistência de processos interdependentes, mas em um sentido mais fraco: cada sistema é construído sobre um conjunto de elementos primitivos próprios, sua própria família de conceitos, operações e processos (JACKENDOFF, 1990). 
${ }^{3}$ Esse princípio corresponde à "grammatical constraint" de JACKENDOFF (1983, p. 13-16; p. 59-63), que basicamente assumo, embora não possa acompanhá-lo em todas as conseqüências que o autor tira dele. De fato, se é verdade que a explicação de fenômenos sintáticos das línguas naturais não se beneficia diretamente de uma semântica referencial ou denotacional (ver, também, CHOMSKY, 1995-a), não há por que excluí-la, como irrelevante para os objetivos de uma teoria da linguagem. Embora uma tradição filosófica abandone uma análise linguístico-gramatical, por considerar a formalização como um processo de "higienização" das línguas naturais "confusas, ambíguas e vagas", em outra se assumem princípios metodológicos similares à "grammatical constraint". Assim, MONTAGUE, (1968) ou mais recentemente KAMP (1981): aquele, realizando um esforço de aproximar uma sintaxe e semântica formais da construção e interpretação das expressões das línguas naturais; este, reconstruindo a teoria semântica para tornar suas representações mais compatíveis com o ponto de vista lingüístico e psicológico do processo de interpretação. Vejam-se, ainda, PARTEE (1979, 1980), DOWTY (1979, 1-2), BACH (1981), VERKUYL (1985), KAMP e REYLE (1993).

${ }^{4}$ Assim entendem, entre outros, EMONDS (1985), CHOMSKY (1995-b, p. 312-316; BRODY (1995, p. 13-18).

${ }^{5}$ Utilizo os termos metateóricos - categorias, relações e funções - com um sentido determinado. "Categorias" refere-se a propriedades ou conjuntos de propriedades estruturadas que permitem agrupar elementos de uma "coleção" (APOSTEL, 1967) em conjuntos ou classes: no sentido saussureano, um princípio de classificação. "Relações" tem um sentido construtivo: traduz o liame entre elementos que estruturam um conjunto e permitem construir objetos complexos a partir de objetos simples do sistema. "Funções": refere-se aos papéis determinados para os elementos pelas relações que contratam nas unidades complexas ("Functivos" em HJEMSLEV, 1966, p. 49). Nesse sentido é que predicado e sujeito são sempre termos funcionais. Ver CHOMSKY, 1965, p. 63-75; FRANCHI, 1976, p. 73-74, 84-85.

${ }^{6}$ Essa contraposição é semelhante à que fazem CHIERCHIA (1984, p. 65 e sgs.), entre predicados e operadores, e WILLIAMS (1995, p. 44-45) entre predicados e functores, para evitar ultrapassar uma lógica de primeira ordem. Sobre a noção de coordenadas referenciais, ver LEWIS (1972).

7 Essas relações são privilegiadas nas gramáticas funcionalistas (v. entre tantos outros, HALLIDAY, 1967-68, 1985; GIVÓN, 1979, 1984; ILARI, 1974, 1992; e a bibliografia neles citada. Um tratamento formal na teoria de princípios e parâmetros pode-se ver em RIZZI, 1995.

${ }^{8}$ Este é o objetivo de Franchi em livro a sair. 